\title{
PHOTOMETRIC CLASSIFICATION OF STARS IN THE VILNIUS OBSERVATORY
}

\author{
V. STRAIŽYS \\ Vilnius Astronomical Observatory, Lithuania, U.S.S.R.
}

(Read by A. Ardeberg)

\begin{abstract}
The programs of three-dimensional classification of stars using eight-color intermediate band photometric system are described. They include (1) investigation of interstellar reddening and absorption in the direction of objects significant from point of view of stellar evolution, (2) investigation of spatial distribution of stars of different spectral classes, luminosities and chemical composition, (3) the detection of unique objects.
\end{abstract}

The multicolor intermediate band photometric system developed in Vilnius observatory can be used for purely photometric determination of stellar spectral classes, absolute magnitudes, chemical composition parameter and interstellar reddening. The system is described in a series of papers which appeared in Vilnius Observatory Bulletins. The most recent general description of the system is given by Straižys (1970) and Straižys, Sviderskienè (1971). The response curves of the system are given by Straižys and Zdanavičius (1970), the calibration of reddening-free diagrams $Q, Q$ and two-color diagrams in spectral classes and absolute magnitudes - by Sviderskienè and Straižys (1971), the method of classification of stars in chemical composition - by Bartkevičius and Straižys (1970a, b, c, d). The general scheme of three dimensional classification of any collection of stars, including the samples of different temperatures, luminosities, populations, interstellar reddenings and some kinds of peculiarities, is given by Straižys and Sviderskienè (1971). Now we generally use eight filters marked by $U, P, X, Y, Z, V, T, S$ with mean wavelengths at $345,374,405,466,516,544,625$ and $655 \mathrm{~nm}$, however for different tasks less quantity of the filters is sufficient.

In 1967-1970 the photoelectric observations of about 900 stars for calibration purposes were obtained (Zdanavičius et al., 1969; Bartkevičius and Metik, 1969; Sūdžius et al., 1970; Straižys et al., 1970; the remaining unpublished). Since 1971 we have started a research programs described below.

TABLE I

Numbers of BS-stars having no published MK spectra

\begin{tabular}{rrr}
$V$ & $\delta>0$ & $\delta<0$ \\
\hline$<5.0$ & 50 & 130 \\
$5.0-5.5$ & 240 & 340 \\
$5.5-6.0$ & 630 & 730 \\
$>6.0$ & 1040 & 1460 \\
Total & 1960 & 2260
\end{tabular}

Ch. Fehrenbach and B.E. Westerlund (eds.), Spectral Classification and Multicolour Photometry, 183-185. All Rights Reserved. Copyright O 1973 by the IAU. 
One of our first programs accessible to small telescopes is two and three dimensional classification of BS stars without published MK spectra (Table I). Up to now photoelectric observations of about 200 stars are obtained.

The Vilnius observatory system gives the possibility to investigate the structure of the Galaxy in crowded regions of the Milky Way and to reach stars too faint for MK classification from the spectra. Now we are measuring the stars up to $13^{\mathrm{m}}$ with photomultiplier EMI 9502 working as a photoncounter with a $70 \mathrm{~cm}$ reflector. The replacement of glass filters by the interference ones with maximum transmission about $70-80 \%$ will add at least $1^{\mathrm{m}}$. Thus in the near future we shall be able to obtain three dimensional classification of stars up to $15-15^{\mathrm{m}} .5$ with a $160-\mathrm{cm}$ reflector.

Such faint stars accessible permit to solve the following problems.

(1) To investigate interstellar reddening and absorption in the direction of objects significant from point of view of stellar evolution. Such objects are globular clusters, pulsars, galaxies, quasars, novae and supernovae, some unique stars (both constant and variable), etc. In the most cases interstellar absorption up to these objects is known only approximately and it is impossible to obtain exact intrinsic energy distribution in their spectra. This problem can be solved by the use of small number (20-30) of faint stars around the object under investigation and distributed up to distance of the object, if it is inside our Galaxy, or up to Galaxy boundary, if it is extragalactic object.

(2) To investigate spatial distribution of stars of different spectral classes, luminosities and chemical composition into different directions from the Sun, including the variation of spatial structure of the Galaxy with $z$-coordinate, approaching the spiral arms or the center of the Galaxy. These investigations are, however, much more laborious because observations of hundreds of stars are needed. On the other hand, they will give much more exact results than earlier methods because the individual distance moduli of stars will be used instead of statistical ones.

(3) To reveal unique objects. During the investigation of interstellar absorption or spatial structure of the Galaxy the stars will be found which will be useless for the investigation due to their pecularity but very valuable from the astrophysical point of view. They can be extremely metal-deficient stars, $\mathrm{CH}$-stars, barium stars, double and multiple stars of different types, variable stars of different types, emission-line stars, Wolf-Rayet stars, P Cygni stars, symbiotic stars etc. After photometric detection they can be investigated in detail by spectrophotometry and other methods.

The works in Vilnius observatory which are already started or are being planned are concentrated on the solution of the listed problems. In the near future we are planning to investigate the interstellar absorption in the direction of some infrared stars, globular clusters lying near the Milky Way and the galaxies of the Local group. The observations up to $13^{\mathrm{m}}$ are already made in the region of infrared star NML Cyg and another region near the Great Cygnus Rift including open cluster IC 4996 and the star P Cygni.

In collaboration with Radioastrophysical Observatory of Latvian Academy of Sciences in Baldone and the Main Astronomical Observatory of Ukrainian Academy of Sciences near Kiev we are investigating the possibility to realize the Vilnius observa- 
tory system photographically. The application of electronography seems very promissing also.

Note added in proof. The results of two-dimensional classification of 530 stars are published by Zdanavičius et al.: 1972, Bull. Vilnius Obs., No. 34, 3.

\section{References}

Bartkevičius, A. and Metik, L. P.: 1969, Bull. Vilnius Obs., No. 26, 13. Bartkevičius, A. and Straižys, V.: 1970a, Bull. Vilnius Obs., No. 28, 33. Bartkevičius, A. and Straižys, V.: 1970b, Bull. Vilnius Obs., No. $30,3$. Bartkevičius, A. and Straižys, V.: 1970c, Bull. Vilnius Obs., No. 30, 16. Bartkevičius, A and Straižys, V.: 1970d, Bull. Vilnius Obs., No. 30, 33. Straižys, V.: 1970, Bull. Vilnius Obs., No. 28, 6.

Straižys, V., Drazdys, R., and Gurklyté, A.: 1970, Bull. Vilnius Obs., No. 29, 10.

Straižys, V. and Sviderskienè, Z.: 1972, Astron. Astrophys. 17, 312.

Straižys, V. and Zdanavičius, K.: 1970, Bull. Vilnius Obs., No. 29, 15.

Sūdžius, J., Zdanavičius, K., Sviderskiené, Z., Straižys, V., Bartkevičius, A., Zitkevičius, V., Kavaliauskaité, G., and Kakaras, G.: 1970, Bull. Vilnius Obs., No. 29, 3.

Sviderskienè, Z. and Straižys, V.: 1971, Bull. Vilnius Obs., No. $31,3$.

Zdanavičius, K., Sũdžius, J., Sviderskiené, Z., Straižys, V., Burnasov, V., Drazdys, R., Bartkevičius, A., Kakaras, G., Kavaliauskaité, G., and Jasevičius, V.: 1969, Bull. Vilnius Obs., No. 26, 3. 